\title{
THE OCTOBER MEETING IN MIDDLETOWN
}

The seven hundred sixteenth meeting of the American Mathematical Society was held at Wesleyan University, Middletown, Connecticut, on Saturday, October 26, 1974. There were 141 registrants including 108 members of the Society.

By invitation of the Committee to Select Hour Speakers for Eastern Sectional Meetings, there were two one-hour addresses. Professor Mark Kac of Rockefeller University spoke on Some analytic problems suggested by statistical mechanics; he was introduced by Professor Shizuo Kakutani. Professor Philip J. Davis of Brown University spoke on Geometry, computer graphics, and theorems of visual type; he was introduced by Dr. Roy L. Adler.

Professor Ernest G. Manes of the University of Massachusetts, Amherst, organized a special session on Category Theory Applied to Analysis and Topology. Speakers were Professors John Isbell, John Kennison and Joan Wick Pelletier.

There were two sessions for contributed ten-minute papers, chaired by Professors Roger W. Hansell and Ernest C. Schlesinger.

There was a concurrent meeting of the Association for Women in Mathematics.

There was a no-charge lunch and a no-charge cocktail party.

Middletown, Connecticut

WALTER GOTTSCHALK Associate Secretary

\section{THE NOVEMBER MEETING IN NASHVILLE}

The seven hundred seventeenth meeting of the American Mathematical Society was held at Vanderbilt University, Nashville, Tennessee on Friday and Saturday, November $8-9,1974$. There were 332 registrants including 287 members of the Society. Chancellor Alexander Heard greeted the gathering and presented an award to Mrs. Joseph E. Walsh who gave to Vanderbilt University the mathematical collected works of the late Professor J. E. Walsh.

Hour addresses were given by Professor Robert B. Gardner of the University of North Carolina, Professor Trevor Evans of Emory University and Professor James Retherford of Louisiana State University at Baton Rouge. They were introduced by, respectively, Professors Robert Mann, John Neuberger and Charles McArthur.

Three special sessions were held. The first special session was on Combinatorial Theory, organized and chaired by Professor J. V. Brawley of Clemson University. Another special session, Approximation Theory, was organized and chaired by Professor Richard Varga of Kent State University. The third special session, Number Theory, was organized and chaired by Professor Robert McConnel of the University of Tennessee.

Sessions for contributed papers were chaired by Professors C. E. Aull, John L. Bryant, Robert Gilmer, Ann Grams, Joseph S. Morrell, Joe L. Mott, James A. Renecke, Steven Saxon, and J. E. Vaughan.

The local committee consisted of Professors B. F. Bryant, chairman, R. L. Hemminger E. B. Shanks, and J. R. Wesson. 